\section{REVISTA CIENTÍFICA RURAL}

ISSN: $1413-8263 \quad 2525-6912$
Revista Técnico-Científica

\title{
DETERMINAÇÃO DOS COMPONENTES DE PRODUÇÃO DO MILHO DE PRIMEIRA SAFRA, SUBMETIDOS A DIFERENTES ESPAÇAMENTOS E DENSIDADES POPULACIONAIS
}

\author{
${ }^{1}$ Martios Ecco, ${ }^{2}$ Paulo Henrique Lengert, ${ }^{3}$ Guilherme Borghetti Calixto, ${ }^{4}$ Pablo Kieling, ${ }^{4}$ Elvis Martini \\ ${ }^{1}$ Professor Dr. do curso de Agronomia da Pontifícia Universidade Católica do Paraná, campus Toledo, Avenida da União, 500, \\ 85902-532, Toledo, PR. E-mail: ecco.martios@pucpr.br; “Engenheiro agrônomo pela Pontifícia Universidade Católica do \\ Paraná, campus Toledo, Avenida da União, 500, 85902-532, Toledo, PR. E-mail: paulo_093@hotmail.com; ${ }^{3}$ Mestrando em \\ Agronomia pela Universidade Estadual do Oeste do Paraná - UNIOESTE, Programa de Pós-Graduação em Agronomia, \\ Centro de Ciências Agrárias, Rua Pernambuco, 1777 - Caixa Postal: 91, CEP: 85960-000 - Marechal Cândido Rondon - PR \\ E-mail: calixto_gui@outlook.com; ${ }^{4}$ Estudantes do curso de Agronomia da Pontifícia Universidade Católica do Paraná, campus \\ Toledo, Avenida da União, 500, 85902-532, Toledo, PR. E-mails: pkieling@hotmail.com; martinielvis@outlook.com
}

RESUMO: A adoção de espaçamentos com menores e maiores densidades de semeadura estão cada vez mais presentes na agricultura, sendo de extrema importância identificar qual o melhor arranjo de plantas a se utilizar. O objetivo deste trabalho foi determinar o melhor espaçamento e densidade a ser utilizado a fim de se obter melhores componentes de produção e produtividade final. O delineamento experimental adotado foi em blocos ao acaso, em esquema de parcelas subdivididas e quatro repetições. As parcelas foram constituídas por três espaçamentos entre linhas $(0,50 ; 0,70$ e $0,90 \mathrm{~m})$ e as subparcelas, foram constituídas por quatro densidades populacionais (40 mil, 60 mil, 80 mil e 100 mil plantas por hectare), totalizando 12 tratamentos. No momento da colheita, forma mensuradas dentro da área útil de cada parcela a altura de inserção de espiga, diâmetro de colmo, número de fileiras de grãos por espiga, número de grãos por fileira, massa de mil grãos e por fim a produtividade. Após coletados as informações, os dados foram submetidos a análise de variância e ao teste de regressão a $5 \%$ de probabilidade. A interação espaçamento x população não obtiveram diferença significativa. As diferentes populações avaliadas foram significativas para todos os componentes de produção, já para o espaçamento só não houve diferença significativa para comprimento de espiga, diâmetro de espiga e massa de mil grãos. As maiores densidades não proporcionaram acréscimos nos componentes de produção, devido possivelmente a competição por fatores vitais. Entretanto, a alta densidade de 80 mil plantas por hectare proporcionou o maior incremento de produtividade de grãos.

Palavras-chave: Cereais. População. Produtividade. Zea mays 


\title{
DETERMINATION OF THE PRODUCTION COMPONENTS OF MAIZE OF THE FIRST CROP, SUBMITTED TO DIFFERENT SPACING AND POPULATION DENSITIES
}

\begin{abstract}
The adoption of spacings with smaller and higher seeding densities are increasingly present in agriculture, and it is extremely important to identify the best arrangement of plants to be used. The objective of this work was to determine the best spacing and density to be used in order to obtain better production components and final productivity. The experimental design was a randomized block design, with a split - plot scheme and four replications. The plots consisted of three spacings $(0.50,0.70$ and $0.90 \mathrm{~m})$ and the subplots were composed of four population densities (40 thousand, 60 thousand, 80 thousand and 100 thousand plants per hectare), totaling 12 treatments. At the time of harvesting, the height of spike insertion, stalk diameter, number of rows per spike, number of grains per row, mass of one thousand grains and finally productivity were measured within the useful area of each plot. After the information was collected, the data were submitted to analysis of variance and to the regression test at $5 \%$ probability. The different populations evaluated were significant for all the production components, but for the spacing only there was no significant difference for ear length, ear diameter and mass of a thousand grains. The higher densities did not provide increases in the production components, possibly due to the competition for vital factors. However, the high density of 80,000 plants per hectare provided the greatest increase in grain yield.
\end{abstract}

Keywords: Cereals. Population. Productivity. Zea mays.

\section{INTRODUÇÃO}

O milho é um dos principais cereais cultivados em todo Brasil, é de grande importância ao agronegócio mundial devido ser considerado o principal insumo na fabricação de ração animal. Todavia, inúmeros fatores contribuem para cultivá-la, dentre eles pode se destacar os fatores de época de semeadura, cultivar, fertilidade do solo, controle fitossanitários utilizados e densidade de plantas. Para que se possa obter uma maior produção de grãos é necessário que todos esses fatores estejam adequados para cultivá-la, caso um desses esteja abaixo do necessário, este será o responsável pela limitação da produção (ARGENTA et al., 2001).

Apesar da grande variabilidade na adoção de diferentes espaçamentos, pesquisas apontam vantagens para a redução do espaçamento, especialmente quando se elevam as densidades de semeadura devido ao maior rendimento de 
grãos e aproveitamento da luz solar, assim como água, nutrientes, controle de plantas daninhas e erosão (GUARESCHI et al., 2008).

Para se obter um incremento na produção de milho se deve aumentar a eficiência fotossintética das plantas, isso pode ocorrer com uma melhoria da interceptação da radiação fotossinteticamente ativa, pela conversão mais eficiente da radiação interceptada em matéria seca e pela participação de foto assimilados nos órgãos reprodutivos (TEIXEIRA et al., 2015). A cultura do milho pode se beneficiar desses fatos adotando-se um adequado arranjo populacional, podendo ser uma das práticas mais importantes visando maior produtividade (MARCHÃO et al., 2005).

O cultivo de milho safrinha do ano de 2009 , teve $37 \%$ das lavouras cultivado sob espaçamento reduzido $(0,45$ a $0,50 \mathrm{~m})$ e o restante sob espaçamento convencional de 0,70 a 0,90 m (CRUZ et al., 2010). No milho de verão essa tendência deve se manter, tendo em vista da maior facilidade da adequação da semeadora, que não necessita ter as linhas redirecionadas, e também por manterem um potencial produtivo igual ou até mesmo superior aos espaçamentos maiores.

Nos últimos anos, algumas modificações nos espaçamentos e densidades de semeadura proporcionaram um aumento na produção de milho, em relação aos espaçamentos e de densidades tradicionais utilizados, tornando-se uma forma viável captação de nutrientes e outros fatores, devido uma melhor distribuição ainda sem contar com uma maior facilidade de controle de plantas invasoras (CRUZ et al., 2010; TAKASU et al., 2014; KOPPER et al., 2017).

Portanto, este trabalho teve como objetivo determinar o melhor espaçamento e densidade de semeadura a ser utilizado a fim de se obter melhores componentes de produção e produtividade final.

\section{MATERIAL E MÉTODOS}

Este experimento foi conduzido em condições de campo, na unidade experimental do curso de Agronomia da Pontifícia Universidade Católica do Paraná,

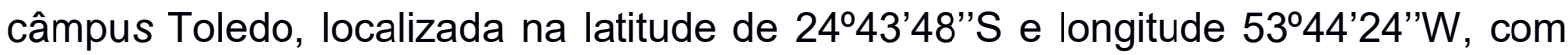
altitude média de 560 m. A classificação climática do local, segundo Köppen é do tipo "Cfa", com predominância de clima subtropical, temperatura média no mês mais 
frio inferior a $19{ }^{\circ} \mathrm{C}$ e temperatura média no mês mais quente acima de $22^{\circ} \mathrm{C}$, com verões quentes, geadas pouco frequentes e tendência de concentrações de chuvas nos meses de verão, contudo sem estação seca definida (CAVAGLIONE, 2000).

O solo da unidade experimental foi classificado como Latossolo Vermelho Distroférrico típico, textura muito argilosa, relevo suave ondulado (EMBRAPA, 2006). Previamente a instalação do experimento, foi realizada a coleta de amostra de solo de $0-20 \mathrm{~cm}$ e encaminhada para avaliação da fertilidade conforme metodologia de Lana et al. (2010), o qual apresentou os seguintes resultados: $\mathrm{pH}$ em $\mathrm{CaCl}_{2}$ 0,01 mol $\mathrm{L}^{-1}$; 4,90; C: 20,16 $\mathrm{g} \mathrm{dm}^{-3}$; P: 11,40 mg dm dm $^{-3}$ T: 11,39; V\%: 55.14\%; Ca, Mg, K e H +

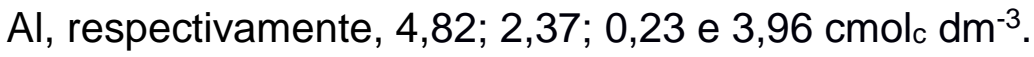

O delineamento experimental adotado foi em blocos ao acaso, em esquema de parcelas subdivididas com quatro repetições. As parcelas foram constituídas por três espaçamentos entre linhas $(0,50 ; 0,70$ e $0,90 \mathrm{~m})$ e as subparcelas, foram constituídas por quatro densidades populacionais (40,60, 80 e 100 mil plantas por hectare), totalizando 12 tratamentos. A adubação foi realizada conforme a exigência da cultura, na qual para a semeadura utilizou-se $700 \mathrm{~kg} \mathrm{ha}^{-1}$ do formulado 08-15-15, já para a adubação de cobertura utilizou-se sulfato de amônio (22\% de $\mathrm{N}$ e $22 \%$ de S), na dose de $75 \mathrm{~kg} \mathrm{ha}^{-1}$ no estádio V4. O híbrido utilizado foi o PIONEER P2530, tratados com inseticidas a base de Clotianidina e Fipronil.

Para o espaçamento de $0,50 \mathrm{~m}$ entre linhas, cada parcela apresentou uma área de $30 \mathrm{~m}^{2}$, constituída de 6 linhas de $6 \mathrm{~m}$ de comprimento, onde foi considerado para as avaliações as 4 linhas centrais; no espaçamento de $0,70 \mathrm{~m}$ entre linhas, cada parcela com $30 \mathrm{~m}^{2}$, constituída de 5 linhas de $6 \mathrm{~m}$ de comprimento, considerado para as avaliações as 3 linhas centrais e no espaçamento de $0,90 \mathrm{~m}$ entre linhas, cada parcela com $30 \mathrm{~m}^{2}$ constituída de 4 linhas de $6 \mathrm{~m}$ de comprimento, sendo considerado para as avaliações as 2 linhas centrais, excluindo-se, em cada espaçamento, $1 \mathrm{~m}$ de cada extremidade.

A semeadura foi realizada no dia 09 e 10 de setembro de 2014, com as parcelas previamente riscadas por uma semeadora. Os tratos culturais realizados foram capina manual em pós-emergência para o controle de plantas daninhas, já para o controle de pragas foram aplicados os inseticidas (Metomil e Imidacloprido + 
Beta-Ciflutrina) aos 9 DAS e o inseticida (Triflumurom e Metomil) aos 23 DAS. As aplicações foram realizadas com a utilização de pulverizador costal de $20 \mathrm{~L}^{-1}$.

Durante a condução do experimento as médias mensais de temperatura mínima foram acima de $18{ }^{\circ} \mathrm{C}$ e as máximas abaixo dos $33^{\circ} \mathrm{C}$, já a precipitação se manteve entre 80 e $150 \mathrm{~mm}$, apenas no mês da semeadura onde teve um pico de $350 \mathrm{~mm}$, o que favoreceu para a formação do estande.

Os componentes de rendimento do milho foram determinados no momento da colheita, sendo selecionados aleatoriamente dentro de cada parcela 10 plantas, nas quais foram medidos os seguintes componentes: (1) altura de inserção de primeira espiga, que foi realizada com auxílio de uma trena fixada a uma tábua, esta medida foi mensurada em metros desde o solo (colo da planta) até a extremidade da inflorescência masculina e o ponto de inserção do colmo com a espiga principal. (2) diâmetro de colmo, foi mensurado com auxílio de um paquímetro, tomando-se a medida em centímetros, mensurado na altura do primeiro entrenó acima do nível do solo. (3) número de fileiras de grãos por espiga e (4) número de grãos por fileira foi obtido por contagem manual de 10 espigas.

A contagem de mil grãos (5) foi realizada manualmente onde foram contadas três amostras de cada parcela para que o resultado da média possa ser utilizado. Para determinação da produtividade $\left(\mathrm{kg} \mathrm{ha}^{-1}\right)(6)$, foram debulhadas as espigas da área útil $\left(30 \mathrm{~m}^{2}\right)$ de cada parcela com o auxílio de uma trilhadeira, e os grãos foram pesados em uma balança digital obtendo-se a produção por parcela, onde corrigiuse a umidade para $13 \%$.

Os dados foram tabulados e submetidos a análise de variância em função do nível de $5 \%$ de significância pelo Teste de $\mathrm{F}$, e as médias quantitativas submetidas ao teste de regressão a $5 \%$ de probabilidade. As análises foram executadas utilizando o programa estatístico SISVAR 5.4 - Sistemas para análise de variância (FERREIRA, 2011), e as figuras realizadas no Excel 2007.

\section{RESULTADOS}

Para o milho de primeira safra, o manejo de diferentes espaçamentos entre linhas e densidades de plantas promoveram efeito significativos $(p<0,05)$ para 0 milho (Tabela 1), sendo que, para espaçamento entre plantas as variáveis 
influenciadas foram; Altura de inserção de espiga (AIE), Diâmetro de colmo (DC), Número de fileiras de grãos por espiga (NF), número de grãos por fileira (NGF) e Produtividade (Prod), entretanto, não houve efeito significativo para a variável massa de mil grãos (MMG). Já para densidade de plantas todas as variáveis promoveram efeito significativos $(p<0,05)$. A interação espaçamento $X$ Densidade não proporcionou efeitos significativos $(p>0,05)$ para as variáveis analisadas.

Tabela 1. Médias, média geral, valores de $\mathrm{F}$ e coeficiente de variação (CV) para as variáveis; Altura de inserção de espiga (AIE), Diâmetro de colmo (DC), Número de fileiras de grãos por espiga (NF), número de grãos por fileira (NGF), Massa de mil grãos (MMG) e Produtividade (Prod) em função dos diferentes espaçamentos entre linhas e densidades de plantas, cultivada em Toledo - PR, Campo

Experimental da Pontifícia Universidade Católica do Paraná, safra 2014/15.

\begin{tabular}{ccccccc}
\hline Fontes de variação & $\begin{array}{c}\text { AIE } \\
(\mathrm{m})\end{array}$ & $\begin{array}{c}\mathrm{DC} \\
(\mathrm{mm})\end{array}$ & $\mathrm{NF}$ & $\mathrm{NGF}$ & $\begin{array}{c}\text { MMG } \\
(\mathrm{g})\end{array}$ & $\begin{array}{c}\text { Prod } \\
\left(\mathrm{kg} \mathrm{ha}^{-1}\right)\end{array}$ \\
\hline Espaçamento $(\mathrm{m})$ & & & & & & \\
0,5 & 0,94 & 22,72 & 13,68 & 41,64 & 45,82 & 10633,9 \\
0,7 & 0,98 & 21,31 & 13,57 & 40,65 & 45,29 & 8530,1 \\
0,9 & 1,02 & 18,84 & 13,31 & 39,74 & 46,93 & 9397,5
\end{tabular}

Densidade (mil pl $\mathrm{ha}^{-1}$ )

$\begin{array}{ccccccc}40 & 0,92 & 24,64 & 13,92 & 44,58 & 49,43 & 8732,1 \\ 60 & 0,95 & 21,77 & 13,62 & 41,99 & 46,48 & 9259,1 \\ 80 & 1 & 19,63 & 13,43 & 39,15 & 44,67 & 10498,8 \\ 100 & 1,05 & 17,78 & 13,12 & 36,99 & 43,94 & 9592,1\end{array}$

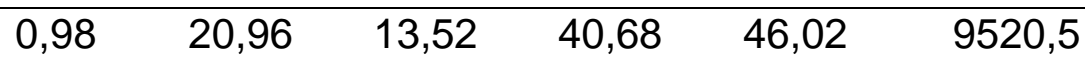

\begin{tabular}{|c|c|c|c|c|c|c|}
\hline Espaçamento & $42,2^{*}$ & $92,5^{*}$ & $6,9^{*}$ & $11,6^{*}$ & $2,1^{\text {ns }}$ & $10,5^{*}$ \\
\hline Grau de Regressão & Linear & Linear & Linear & Linear & - & Quadrática \\
\hline Densidade & $74,5^{\star}$ & $156,2^{*}$ & $16,7^{*}$ & $105,9^{*}$ & $13,4^{*}$ & $3,9^{*}$ \\
\hline Grau de Regressão & Linear & $\begin{array}{l}\text { Quadrát } \\
\text { ica }\end{array}$ & Linear & Linear & $\begin{array}{l}\text { Quadr } \\
\text { ática }\end{array}$ & Linear \\
\hline $\begin{array}{l}\text { Espaçamento X } \\
\text { Densidade }\end{array}$ & $0,7^{\text {ns }}$ & $0,5^{\mathrm{ns}}$ & $0,55^{\text {ns }}$ & $1,63^{\text {ns }}$ & $0,18^{\text {ns }}$ & $1,24^{\text {ns }}$ \\
\hline
\end{tabular}




\begin{tabular}{lllllll}
\hline CV1 (\%) & 2,39 & 3,83 & 2,36 & 2,88 & 5,75 & 18,25 \\
\hline CV2 (\%) & 2,28 & 3,91 & 2,03 & 2,71 & 4,85 & 12,51 \\
\hline
\end{tabular}

Para a altura de inserção de espigas foram observadas diferenças significativas quanto aos espaçamentos (Figura 1a) e densidades (Figura 1b), o qual apresentou equação linear em ambos os casos, ou seja, maiores valores de espaçamento $(0,9 \mathrm{~m})$ e densidade (100 mil plantas ha $\left.{ }^{-1}\right)$ favorecem ao aumento na altura de inserção de espiga.
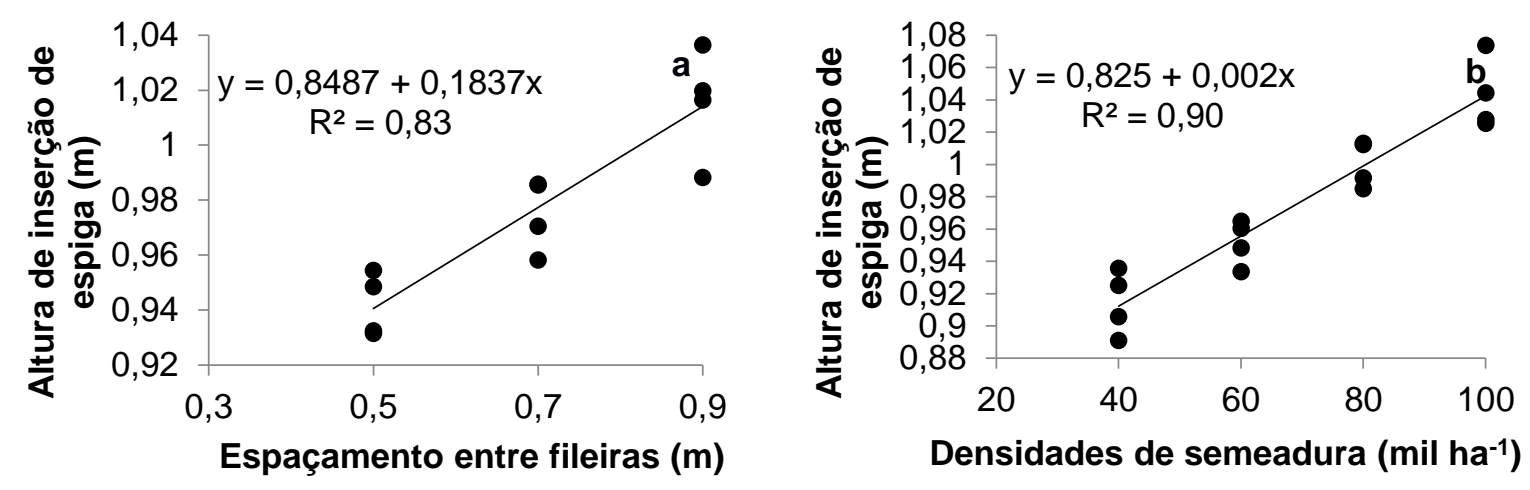

Figura 1. Altura de inserção de espiga (AIE) de plantas de milho submetidas a diferentes espaçamentos (a) e densidades de plantas (b).

O diâmetro de colmo foi influenciado significativamente, apresentando ajuste linear e quadrático, respectivamente, para espaçamento entre linhas (Figura 2a) e, densidade de plantas (Figura 2b). A diminuição do espaçamento entre linhas promove menor diâmetro de colmo devido ao competitividade entre plantas, da mesma forma que o aumento da densidade de semeadura favoreceu menor diâmetro de colmo fazendo com que se tenha colmos com menor diâmetro e suscetíveis a vento e chuva. Derivando esta regressão é possível inferir que em torno de 169 mil plantas por hectares podem proporcionar acréscimo no diâmetro do colmo de $40 \%$ (14,5 mm). 

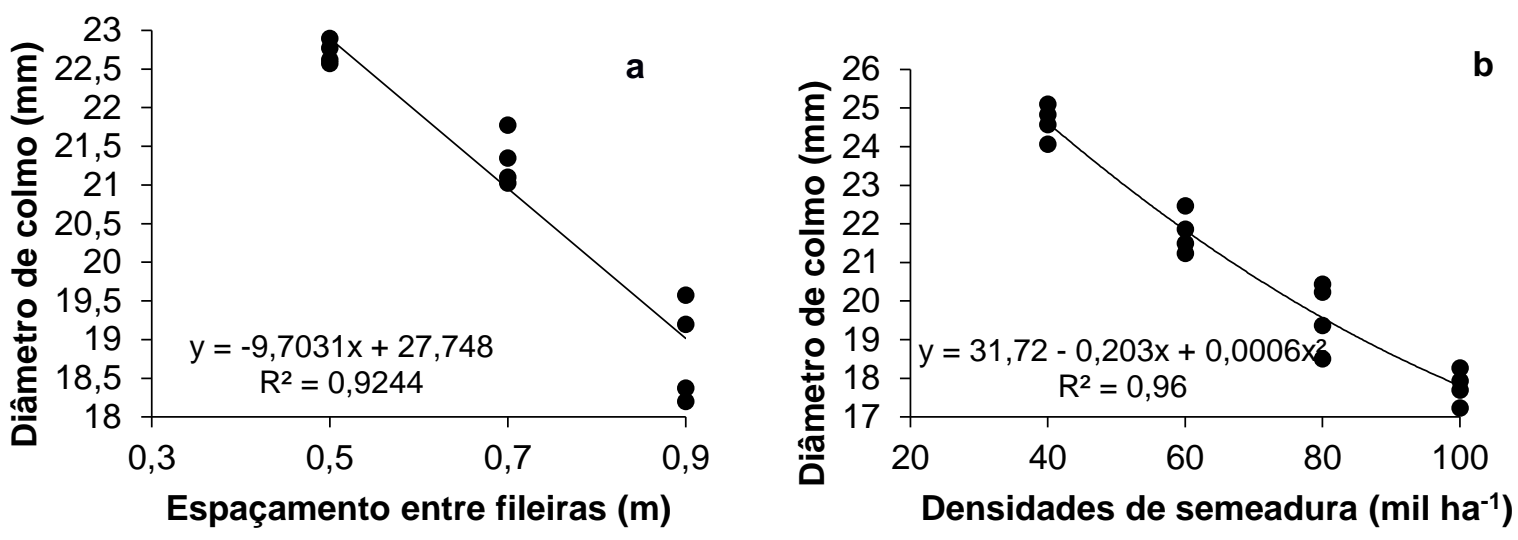

Figura 2. Diâmetro de colmo (DC) de plantas de milho submetidas a diferentes espaçamentos (a) e densidades de plantas (b).

Para o número de fileiras por espiga, observou-se diferença significativa com ajuste linear para equação (Figura 3a) com tendência para aumento do número de fileira com menor espaçamento $(0,5 \mathrm{~m})$ e menor número de fileiras para maior espaçamento $(0,9 \mathrm{~m})$. Já para o número de fileiras em função da densidade de semeadura, houve efeito significativo com ajuste linear da equação (Figura 3b). obtendo uma tendência de um maior valor numérico de fileiras quando submetido a menores densidades de semeadura, portanto, onde se tem menor número de espigas por área se obtêm melhores valores dos parâmetros de produção, no caso se obteve maior número de fileiras por espiga.
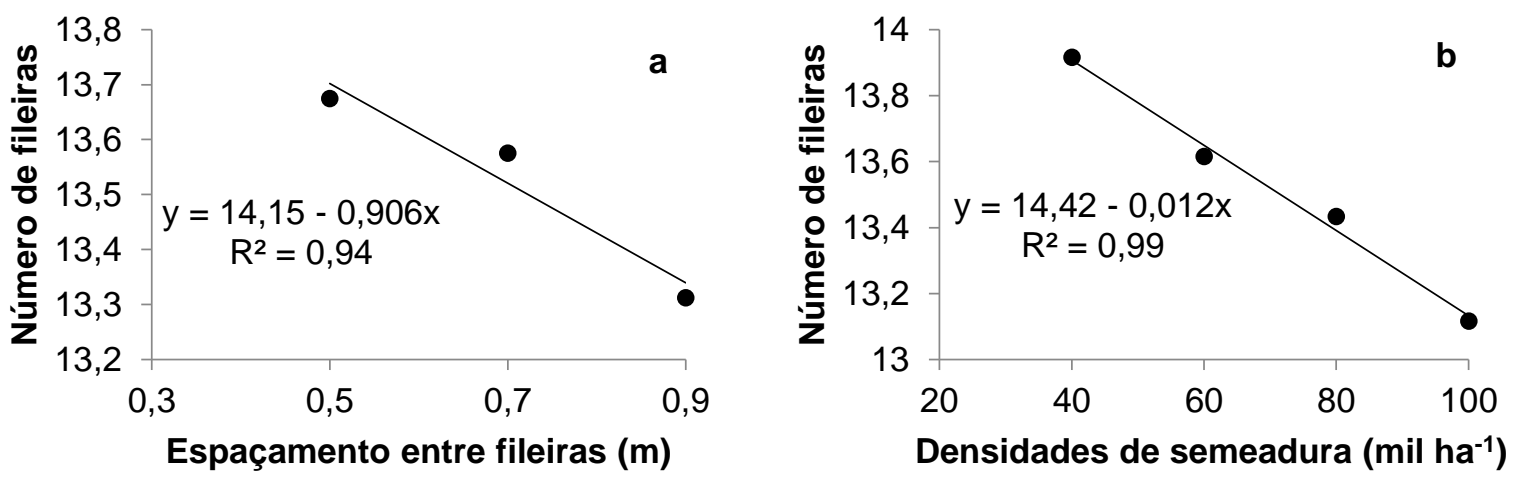

Figura 3. Número de fileiras de grãos por espiga de milho (NF) submetidas a diferentes espaçamentos (a) e densidades de plantas (b). 
O número de grãos por fileira apresentou um ajuste linear para espaçamento entre linhas (Figura 4a), onde o maior valor para variável foi obtida com o menor espaçamento entre linhas $(0,5 \mathrm{~m})$ quando comparados com os demais tratamentos.

Já para número de grãos por fileira em função da densidade de semeadura, o ajuste observado foi linear (Figura 4b), onde a menor densidade de semeadura tem a possuir menos grãos por fileira do que densidade menores, sendo justificado por compensar uma menor quantidade de espigas por área, com maiores valores de componentes de produção, no caso o número de grãos por fileira foi maior para o tratamento com menos espigas por área.
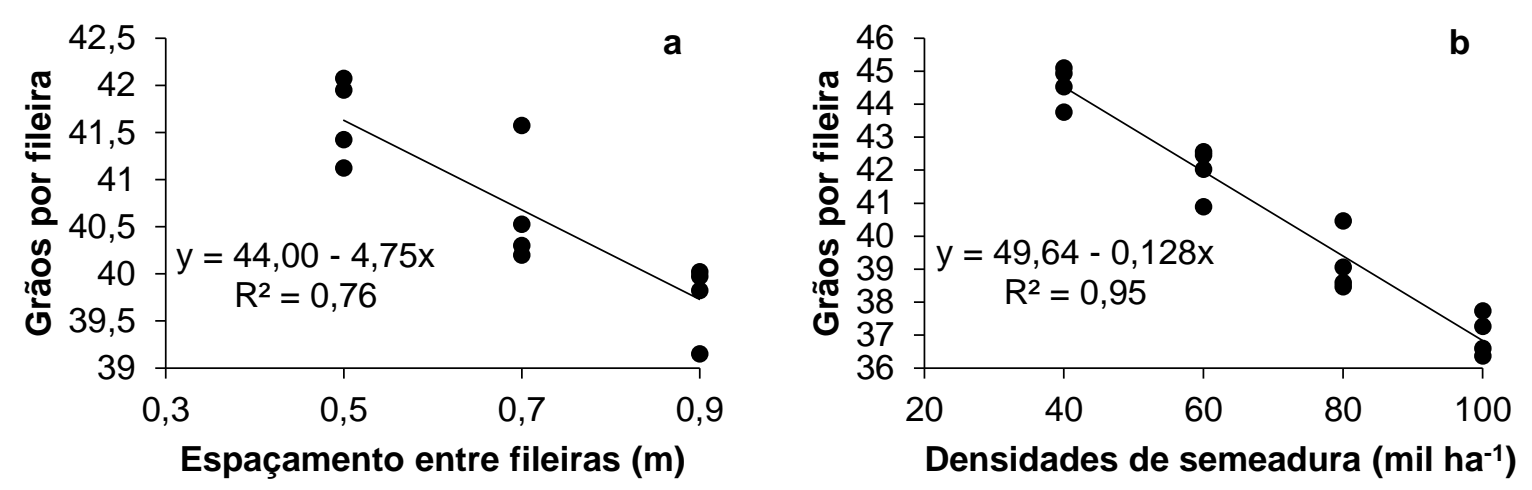

Figura 4. Número de grãos por fileira de espigas de milho (NGF) submetidas a diferentes espaçamentos (a) e densidades de plantas (b).

Para massa de mil grãos houve efeito significativo com ajuste quadrático para densidade de semeadura (Figura 5), na qual observou-se uma tendência no ganho de massa de mil grãos para densidade de 40 mil plantas por ha-1 e com o aumento da densidade se obteve diminuição desta variável. 


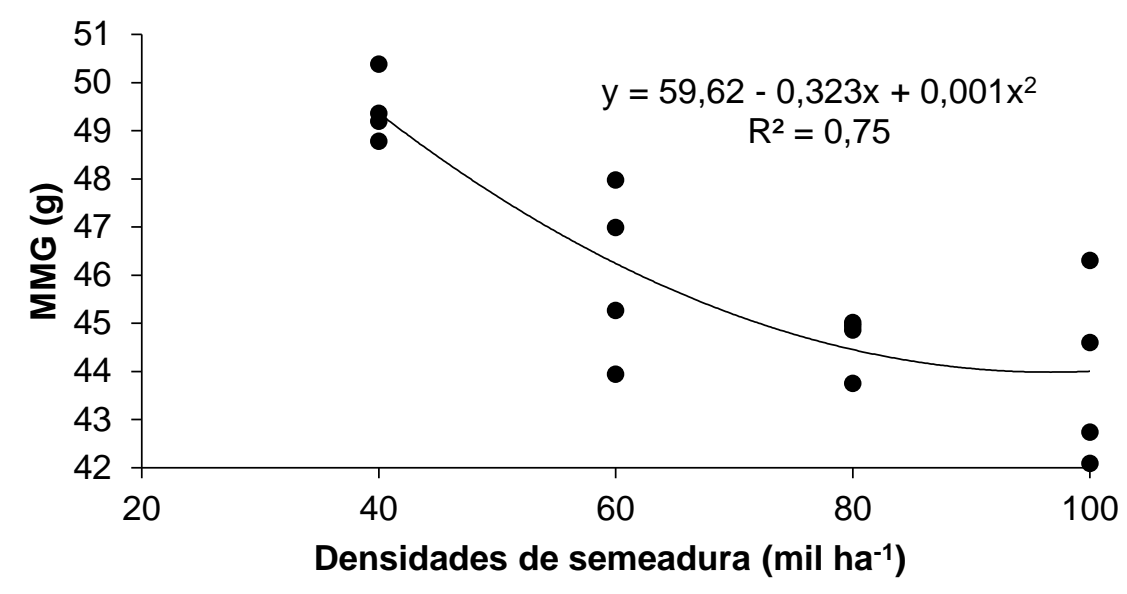

Figura 5. Massa de mil grãos (MMG) de espigas de milho submetidas a diferentes densidades de plantas.

A produtividade foi afetada significativamente entre os diferentes espaçamentos utilizados, na qual observou-se um ajuste quadrático para espaçamento entre fileiras (Figura 6a). Dentre os tratamentos observou-se os maiores valores de produtividade com a diminuição do espaçamento $(0,5 \mathrm{~m})$. Já conforme a derivada da função quadrática, indica que utilizando um espaçamento de $0,74 \mathrm{~m}$ entre fileiras, a produtividade estimada é de $8.465,45 \mathrm{~kg} \mathrm{ha}^{-1}$, sendo o menor valor para esta variável, portanto, não é aconselhável a utilização deste espaçamento.
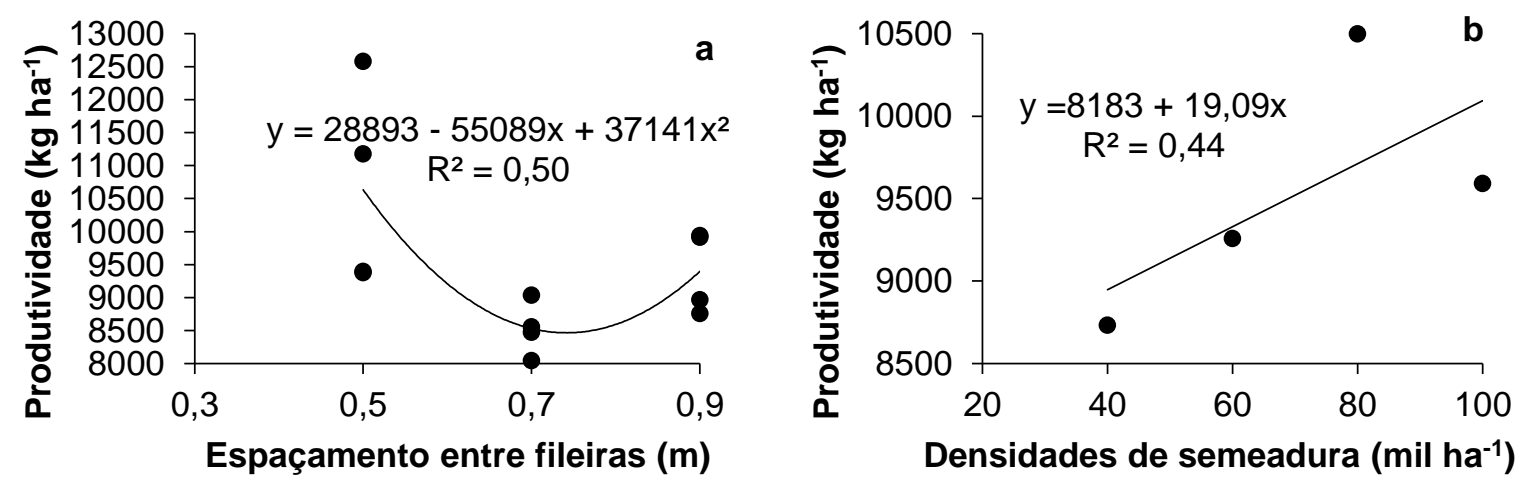

Figura 6. Produtividade de grãos de milho (Prod) submetido a diferentes espaçamentos (a) e densidades de plantas (b).

Já na figura 6b, é possível observar um ajuste linear para a densidade de semeadura, onde que a densidade de 80 mil plantas ha-1 $^{-1}$ foi a que proporcionou a maior produtividade observada, uma vez que menores densidade como 40 mil 
plantas ha-1, apesar de apresentarem resultados superiores para as variáveis anteriormente avaliadas não é compensatória para produtividade devido a menor quantidade de espigas por área.

\section{DISCUSSÃO}

Para densidade de plantas, a altura de inserção de espiga apresentou efeito linear, onde o aumento na densidade de semeadura proporcionou incremento na altura de inserção de espigas, com maiores valores para densidade de 100 mil plantas ha-1 (Figura 1).

Resultados semelhantes ao deste trabalho foi verificado por Demétrio et al. (2008), que de acordo que foi aumentando a densidade populacional de plantas de milho, observaram que houve maior altura de inserção de espiga. Marchão et al. (2005) chegaram aos mesmos resultados onde a maior densidade de semeadura originou maiores alturas de inserção de espiga, Calonego et al. (2011) observaram esta tendência com maiores valores de inserção de espiga para maiores densidades de semeadura.

Modolo et al. (2010), verificaram que os espaçamentos entre fileiras de 0,70 e 0,90 m resultaram em maiores valores de altura de inserção de espiga.

Para a varíavel diâmetro de colmo, Resende et al. (2003) e Stacciarini et al. (2011), notaram uma redução nesta variável nos tratamentos com maior espaçamento entre linhas de semeadura, atribuindo esse fato a competição por luz ser maior devido a maior densidade de plantas na linha de semeadura.

Os resultados de número de fileiras por espiga de milho corroboram com os de Palhares (2003), onde relata que a redução do espaçamento promove um aumento significativo do número de fileiras por espigas, resultado obtido para dois genótipos trabalhados pelo autor; o DKB 911 e o AG 1051. Em relação as diferentes densidades, os resultados corroboram com o efeito abordado na variável anterior (DC), ou seja, com menor densidade de plantas, consequentemente haverá menor número de espigas já que cada planta produzirá ao menos um espiga. Este maior espaço entre as plantas de milho, contribui para maior penetração da luminosidade, podendo proporcionar no periodo vegetativo (V12) maior diferenciação de fileiras de grãos. Neto et al. (2003), observaram em 2 dos 3 genótipos avaliados a mesma 
tendência de redução do número de fileiras por espiga em função do aumento de densidade de semeadura, devido possivelmente pela competição por luz e água. Entretanto, sabe-se que esta variavel está diretamente relacionado com o potencial genético do hibrido.

Marchão et al. (2005) obtiveram resultados semelhantes, ao deste trabalho para a variável número de grãos por fileira (NGF), na qual houve redução do valor desta variável quando aumentado o espaçamento e da densidade. Efeito que se justifica pela melhor distribuição de plantas e melhor utilização dos recursos disponíveis na área. Estes mesmo autores verificaram menores valores para maiores densidades de plantas, assim, concordando com resultado obtido neste trabalho, em que os maiores valores estão nas menores populações avaliadas, sendo justificado por compensar uma menor quantidade de espigas por área, com maiores valores de componentes de produção, no caso o número de grãos por fileira foi maior para o tratamento com menos espigas por área.

A maior massa de mil grãos (MMG) ocorreu em densidades menores, pois possivelmente houve um melhor aproveitamento dos recursos hídricos, da radiação solar, e dos nutrientes dispostos nos solo, onde esse fato foi possível devido ao aumento da densidade de semeadura otimizando o espaço disponível no solo, com maior aproveitamento dos recursos disponíveis. Em trabalho realizado por Demétrio et al. (2008), não obtiveram resultados significativos para a massa de mil grãos em relação aos diferentes espaçamento testados, entretanto avaliando as densidades de semeadura encontraram resultados semelhantes a deste trabalho, onde menores densidades de semeadura possibilitaram a obtenção de grãos mais pesados que os obtidos em densidade de semeadura mais adensadas.

A variável produtividade apresentou acréscimo quando submetido a menor espaçamento e a maior densidade, podendo ser atribuído a melhor distribuição das sementes, onde estas ficam espaçadas entre si de forma mais homogênea, melhorando a absorção de radiação solar, disponibilidade hídrica e utilização dos nutrientes presentes no solo, sem contar a menor competição inter e intra-específica da cultura, proporcionando as plantas menor gasto de energia em competição com plantas daninhas, e maior capacidade de usufruir dos recursos naturais e aplicados ao solo, alcançando assim maiores produtividades. 
Demétrio et al. (2008), avaliaram diferentes espaçamentos de semeadura, onde verificaram a ocorrência positiva da redução do espaçamento entre fileiras de distribuição de plantas e, com populações variando de 75 a 80 mil plantas por ha-1, obtendo maiores produtividades devido ao maior eficiência na interceptação de radiação solar e menor competição por nutrientes água e luz. Resultados semelhantes também foram encontrados por Rocha et al. (2011), em que constataram que o aumento da densidade de plantas até um certo ponto é benéfica, pois mesmo tendo alguns componentes de produção com valores menores que as baixas densidade de semeadura, estas não suprem a maior quantidade de espigas por ha-1.

\section{CONCLUSÕES}

As variáveis analisadas tenderam a apresentarem maiores valores para maiores densidades e espaçamento reduzidos.

Para a produtividade de grãos a densidade de 80 mil plantas ha ${ }^{-1}$ resultou nos maiores valores para este híbrido em estudo cultivado em primeira safra e com espaçamento de $0,5 \mathrm{~m}$.

\section{REFERÊNCIAS}

ARGENTA G.; SILVA P.R.F.; BORTOLINI C.G.; FORSTHOFER E.L.; MANJABOSCO E.A.; NETO. V.B. Respostas de híbridos simples de milho à redução do espaçamento entre linhas. Pesq. Agropec. Bras., Brasília, v.36, n.1, p.71-78, 2001.

ARGENTA, G.; SILVA, P.R F. da; SANGOI, L. Arranjo de plantas em milho: análise do estado da arte. Ciência Rural, Santa Maria, v.31, n.6, p.1075-1084, 2001.

CAVIGLIONE, J.H.; KIIHL, L.R.B.; CARAMORI, P.H.; OLIVEIRA, D. Cartas climáticas do Paraná. Londrina: IAPAR, 2000.

CALONEGO, J.C.; POLETO, L.C.; DOMINGUES, F.N.; TIRITAN, C.S. Produtividade e crescimento de milho em diferentes arranjos de plantas. Revista Agraian, Dourados, v.4, n.12, p.84-90, 2011. 
CRUZ, J. C.; SILVA, G. H. D.; FILHO, I. A. P.; NETO, M. M. G.; MAGALHÃES, P. Caracterização do cultivo de milho safrinha de alta produtividade em 2008 e 2009. Revista Brasileira de Milho e Sorgo, v.9, n.2, p177-188, 2010.

DEMÉTRIO, C.S.; FILHO D.F.; CAZETTA, J.O.; CAZETTA, D.A. Desempenho de híbridos de milho submetidos a diferentes espaçamentos e densidades populacionais. Pesq. agropec. Bras., Brasília, v.43, n.12, p.1691-1697, 2008.

EMBRAPA. Sistema brasileiro de classificação de solos. Rio de Janeiro, Embrapa Solos, 2006. 2ed. 306p.

FERREIRA, D.F. Sisvar Versão 5.4. Lavras: DEX/UFLA, 2011.

GUARESCHI, R.F.; GAZOLLA. P.R.; PERIN, A.; ROCHA, A.C. da. Produção de massa de milho silagem em função do arranjo populacional e adubação. Revista Ciência Agronômica, Fortaleza, v.39, n.3, p. 468-475, 2008.

KOPPER, C.V.; MEERT, L.; KRENSKI, A.; BORGHI, W.A.; OLIVEIRA NETO, A.M. de; FIGUEIREDO, A.S.T. Produtividade de milho segunda safra em função de diferentes velocidades de semeadura e densidade de plantas. Pesq. agropec. pernamb., Recife, v.22, p.1-6, 2017.

LANA, M.C.; FRANDOLOSO, J.F.; FEY, R. ; RICHART, A.; FONTANIVA, S. Análise química de solo e tecido vegetal: metodologias analíticas. 2. ed. Cascavel: EDUNIOESTE, v. 1. 155p., 2010.

MARCHÃO, R.L.; BRASIL, E.M.; DUARTE, J.B.; GUIMARÃES, C. M.; GOMES, J.A. Densidade de plantas e características agronômicas de híbridos de milho sob espaçamento reduzido entre linhas. Goiânia, GO: Escola de Agronomia e Engenharia de Alimentos (UFG), 2005.

MODOLO, A. .; CARNIELETTO, R.; KOLLING, E.M.; TROGELLO, E.; SGARBOSSA Desempenho de híbridos de milho na região sudoeste do Paraná sob diferentes espaçamentos entre linhas. Revista Ciência Agronômica, v 41, n. 3, p. 435-441, 2010.

NETO, D.D.; PALHARES, M. VIEIRA, P.A.; MANFRON, P.A.; MEDEIROS, S.L.P.; ROMANO M. R. Efeito da população de plantas e do espaçamento sobre a produtividade de milho. Revista Brasileira de Milho e Sorgo, v.2, n.3, p.63-77, 2003. 
PALHARES, M. Distribuição e população de plantas e produtividade de grãos de milho. 2003. 90f. Dissertação(Mestrado em Agronomia/Fitotecnia) - Universidade de São Paulo, Piracicaba, 2003.

RESENDE, S.G.; PINHO, R.G.V.; VASCONCELOS, R.C. Influência do espaçamento entre linhas e da densidade de plantio no desempenho de cultivares de milho. Revista Brasileira de Milho e Sorgo, v.2, n.3, p.34-42, 2003.

ROCHA, D.R.; FORNASIER FILHO, D.; BARBOSA, J.C. Efeitos da densidade de plantas no rendimento comercial de espigas verdes de cultivares de milho. Horticultura Brasileira, v.29, n.3, p.392-397, 2011.

STACCIARINI, T.C.V.; CASTRO, P.H.C.; BORGES, M.A.; GUERIN, H.F.; MORAES, P.A.C.; GOTARDO, M. Avaliação de caracteres agronômicos da cultura do milho mediante a redução do espaçamento entre linhas e aumento da densidade populacional. Rev. Ceres, Viçosa, v. 57, n.4, p. 516-519, 2010.

TAKASU, A.T.; RODRIGUES, R.A.F.; GOES, R.J.; ARF, O.; HAGA, K.I. Desempenho agronômico do milho sob diferentes arranjos populacionais e espaçamento entrelinhas. Revista Agrarian, Dourados, v.7, n.23, p.34-41, 2014.

TEIXEIRA, G.C. da S.; STONE, L.F.; HEINEMANN, A.B. Eficiência do uso da radiação solar e índices morfofisiológicos em cultivares de feijoeiro. Pesq. Agropec. Trop., Goiânia, v. 45, n. 1, p. 9-17, 2015. 